of the specimens by the three methods: Mohr's with silver nitrate and potassium chromate (one gram of the specimen being used and the percentage corresponding to the cubic centimeters inserted from the table). Pisani's method with silver nitrate and starch iodide ( $1.655^{6}$ grams being used and each cubic centimeter of $\frac{\mathrm{N}}{\mathrm{I}} \mathrm{AgNO}_{\mathrm{s}}$ deemed equivalent to one per cent. of $\mathrm{KI}$ ) and with the thallous chloride, (0.16556 gram being used and one cc. counted as one per cent.).

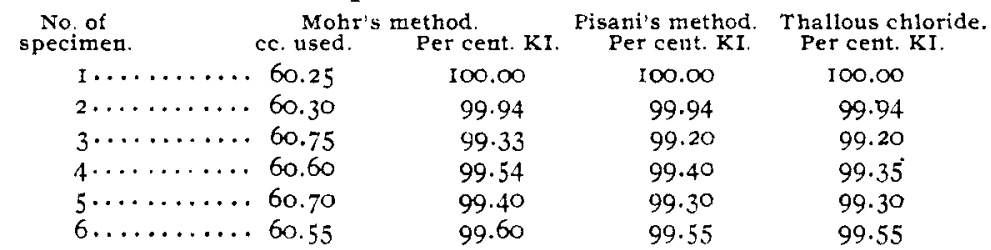

The method of Pisani and that with thallous chloride yielded somewhat less percentages with some of the specimens than Mohr's method, but gave, in almost every instance, results equal to each other.

SAJNT R,OUIS, Mo., July 22, 189.1.

\title{
SEWAGE DISPOSAL AT WORCESTER, MASS.
}

BY HARRISON P. EDDY

Received February' 6 , r894

SINCE the description of the sewage disposal works at Wor$\checkmark$ cester, by Dr. Leonard P. Kinnicutt, in $189 \mathrm{I}$, (See $J$. Anal. Appl. Chem., 5, 544), many important changes have been made both in the methods employed and machinery used. The capacity of the plant has also been greatly increased. The amount of water then dealt with was $3,000,000$ gallons per twenty-four hours, while now between $10,000,000$ and $15,000,000$ gallons are successfully treated in the same time.'

Before examining in detail the work accomplished it may be well to look briefly into the history connected with the purification of sewage at Worcester, that the problems encountered may be more fully understood.

For many years the city turned her sewage directly into the Blackstone river, a stream of about 23,000,000 gallons during

1 Descriptions of this plant showing the engineering details are given in the Engineering News for January is and is and the Engineering Record for January 13, to which the reader is referred. 
the summer months. This stream is fed, in part, by water from the northern water shed which tributary is called Millbrook, and it flows through the center of the city. This water amounts to about $8,000,000$ gallons per day during the summer months. Millbrook being so conveniently situated was made the trunk sewer and to-day all the sewage of Worcester is discharged into it. For a number of years there was so little filth turned into the stream that the villages situated near the river, below the city, had little cause for complaint, but with the increase of population the river became very foul until, in I886, the complaint from neighboring villages was heeded by the Massachusetts Legislature, and the right, granted in 1867 , to turn sewage into the Blackstone river was revoked. An act was passed June 25, I886, compelling Worcester to "remove from its sewage, before it is discharged into the Blackstone river, the offensive and polluting properties and substances therein, so that, after its discharge into said river ${ }^{*} *^{*}{ }^{*}$ it shall not create a nuisance or endanger the public health." Four years were given the city in which to perfect some system for the accomplishment of this result, and accordingly, City Engineer Chas. A. Allen personally inspected works at home and abroad and after a careful study of the local problems recommended that a plant, capable of dealing with $4,500,000$ gallons of sewage daily, be constructed and that the method of treatment employed be that of chemical precipitation.

This plant was first operated June 25, I 890 , from which time until July, I 893 , about $3,000,000$ gallons of sewage were treated daily, except in time of storm when the entire flow was turned directly into the stream. It was found from the experiments of these three years that, by chemical precipitation, the sewage could be purified to an extent which would admit of its being turned into the river. Having settled this point, the next problem confronting the city was the treatment of the entire amount of sewage, as thus far only about twenty per cent. had been taken to the purification works. The actual amount of sewage is between 5,000,000 and 8,000,000 gallons per day, while the water from the brook, mentioned above, increases this to 10,000, $\infty 00$ or $15,000,000$ gallons in dry weather, while in storm this amount is so largely increased that its treatment is wholly out 
of question. The city is almost wholly sewered on the combined plan. From the start the plan had been to separate the waters of Millbrook from the sewage, thus leaving only a moderate amount of water with which to deal. On further consideration, however, it seemed advisable, for the present at least, to take as much of the sewage to the plant as possible. Accordingly, the present city engineer, then superintendent of the sewer department, Mr. F. A. McClure, proposed that ten additional settling basins, with the other necessary appliances, be provided, and that the whole, or as much as possible of the present flow be taken the to works. This plan having been adopted, work was begun in 892 and the enlarged plant put in operation about the middle of July, 1893 , since which time the entire flow has been treated.

The new basins differ somewhat from the old ones, being $166 \frac{2}{3}$ feet long and forty feet wide; the capacity is, however, the same, as are also the general features of construction. The effluent instead of returning to the steps provided in the old plant, is utilized to furnish power for pumping sludge during the day and for running a dynamo at night. A Shone ejector has been provided for pumping the sludge from the new work and part of that from the old. This ejector has proved to be very efficient and is much better adapted to use with sludg: than the submerged centrifugal pumps employed on the original plant, as there is not the danger of clogging. It is run by air furnished by a compressor, power for which is derived from the water-wheel. Thus expense of steam is avoided.

The agitators originally used for mixing the chemicals have been taken out and two new tanks substituted; these are built of quarter-inch boiler steel and are set in masonry. These tanks are each sixteen feet long, eight feet wide, and three feet two inches deep. The bottom is fluted and through each of three valleys runs an iron pipe perforated with quarter-inch holes about fifteen inches apart. These pipes are connected by means of a main, four-inch pipe to an air receiver. Through the holes in these pipes air is blown at a pressure of sixty pounds, although so high pressure is not absolutely necessary and even air taken directly from the compressor has worked satisfactorily. This air agitates the liquid giving it the appearance of boiling. 
The lime is thus thoroughly mixed with the water in the tank and runs from it in the form of milk of lime. The old practice of grinding the lime has been abandoned, it having been found that slaking in water was just as efficient and that a more economical use obtained by this thorough water-slaking before coming in contact with the sewage. By these changes a considerable saving in power used has resulted and, by the more thorough slaking of the lime, the amount required has been reduced about thirty per cent.

The treatment originally adopted as recommended by Engineer Allen, consisted in the addition to the sewage of lime and aluminum sulphate. It has been found, however, that the alumina need not be used, on account of the large quantities of iron sulphate contained in the sewage. This iron sulphate is not evenly distributed through the sewage of the day but comes at stated periods. At night, when the sewage is comparatively weak, that containing the copperas is stored crude in one or two of the settling basins and is used during the day, when there is a scarcity of iron and when otherwise aluminum sulphate should be added. By utilizing this iron sulphate, considerable expense is avoided and a perfectly clear, odorless effluent obtained. Lime alone is now added to the sewage, about 900 pounds being required for each million gallons. The highest grade obtainable is used, as it proves most economical in the end. The chemicals formerly entered the sewage just above the salmon ladder but have since been carried about 200 feet up the sewer, that a more thorough mixture might be obtained.

The chemical precipitation of sewage has been practiced in England for more than twenty-five years and yet, the published results of experiments performed there are so meager as to be practically of no assistance here. Consequently when this method was adopted in Worcester great faith had to be placed in future developments. From the first day the plant was operated, continued experinents have been made; at first these were wholly mechanical and random but it was soon found that a systematic study of the whole problem must be made if the work was to be successful. Accordingly the problems met in actual manipulation are made subjects of special investigation 
in the well-equipped laboratories. That this move has been productive of good is shown by the reduction of nearly fifty per cent. in the cost of treatment, so far as effected by the chemicals used. Analyses of sewage and effuent are made daily. The samples for analysis are each composed of twenty-four portions taken hourly. Thus by averaging results for several days a mean is obtained, so that comparisons may be made with a certainty that the effluents correspond to the sewages. The percentage of impurity removed from the sewage is readily calculated and is indicative of the efficiency of the plant. Records of the analyses are kept in two forms: one is simply the numerical tabulation, the other a graphic illustration showing at a glance the result of treatment over any period of time. It will be noticed, from accompanying Table $\mathrm{A}$, that the sewage dealt with is remarkably strong, considering that about half of it is water coming directly from North Pond. It is also interesting to note that the effluent contains only two and one-half parts per 100,000 parts matter in suspension and that of this only one and one-tenths parts are organic matter. Thus by treatment the organic suspended matter has been removed to the extent of 90.76 per cent. The total dissolved residue and the total and dissolved fixed residue are negative results, undoubtedly due to the large quantity of lime retained in solution in the effluent. From Table $A$ the result of treatment of sewage since July can be followed by months, and the averages are given for the whole period. The work done as shown by the results of these analyses is very good and should fully carry out the object of the plant; viz., not to transform sewage into a potable water, but to abate and finally terminate a nuisance to neighboring villages along the Blackstone river. During the last three years the sludge has been disposed of in various ways and numerous experiments have been performed and are now being carried on, which. for lack of space cannot be described at this time. It may be added that the aim has been to make the plant attractive to the eye by the architecture of the new buildings, the lighting system and the grading around the basins, that the visitor may have his preconceived, erroneous impression of disagreeable sights and odors dispelled. 


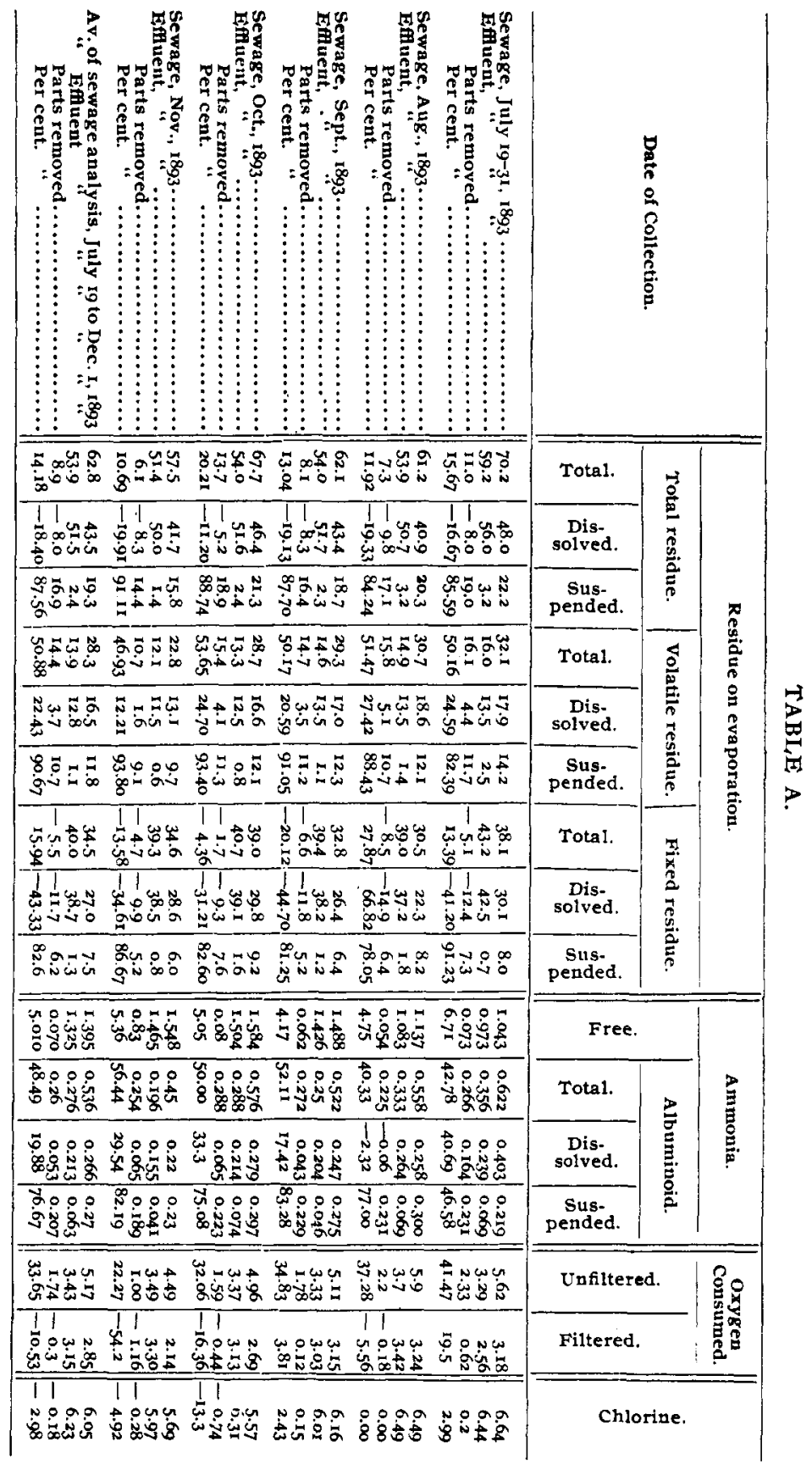

